\section{Molecular Syndromology}

Mol Syndromol 2017;8:206-210

DOI: $10.1159 / 000471247$
Accepted: February 13, 2017

by M. Schmid

Published online: May 10, 2017

\title{
Cantú Syndrome Associated with Ovarian Agenesis
}

\author{
Helena Fryssira ${ }^{a}$ Stavroula Psoni $^{a}$ Styliani Amenta ${ }^{c}$ Eirini Tsoutsou ${ }^{a}$ \\ Christalena Sofocleous ${ }^{a}$ Emmanouil Manolakos $^{d}$ Maria Gavra ${ }^{b}$ \\ Hermann-Joseph Lüdecke ${ }^{\mathrm{e}}$ Johanna-Christina Czeschik ${ }^{\mathrm{e}}$ \\ ${ }^{a}$ Medical Genetics, School of Medicine, and b CT and MRI Department, "Aghia Sophia" Children's Hospital,

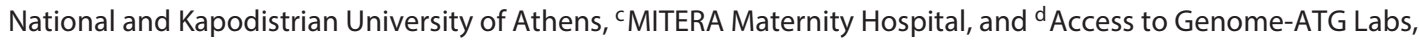 \\ Athens, Greece; ${ }^{\mathrm{e}}$ Institute of Human Genetics, University Clinic, Essen, Germany
}

\section{Keywords}

ABCC9 · Hypertrichosis - Ovaries

\section{Abstract}

Cantú syndrome is a very rare autosomal dominant disorder characterized by generalized congenital hypertrichosis, neonatal macrosomia, coarse face, cardiomegaly, and occasionally, skeletal abnormalities. The syndrome has been attributed to mutated $A B C C 9$ or KCNJ8 genes. We present a 4-year-old girl with developmental delay, distinctive coarse facial features, and generalized hypertrichosis apparent since birth. The investigation revealed absent ovaries and a hypoplastic uterus which have not been previously described. Conventional karyotyping was normal. DNA sequencing analysis of the ABCC9 gene was performed, and a heterozygous point mutation c.3460C $>$ T (p.Arg1154Trp) was revealed. This missense gain-of-function mutation was located in exon 27 of the $A B C C 9$ gene and has been reported in patients with the full phenotype of Cantú syndrome. However, the absence of the ovaries could be an expansion of the phenotype and not attributed to mutations in other genes important for ovarian development. Unfortunately, it has not been proven so far if the $A B C C 9$ gene is expressed in the ovarian tissue.

○ 2017 S. Karger AG, Basel
\end{abstract}

() 2017 S. Karger AG, Basel
Cantú syndrome (OMIM 239850) or hypertrichotic osteochondrodysplasia, first described by Cantú et al. [1982], is characterized by generalized congenital hypertrichosis, neonatal macrosomia, distinctive coarse facial features, cardiomegaly, and skeletal abnormalities [Cantú et al., 1982]. The facial appearance resembles acromegaloid syndromes or storage disorders [Harakalova et al., 2012; van Bon et al., 2012]. To date, about 50 cases with Cantú syndrome have been reported, and heterozygous pathogenic variants in the $A B C C 9$ or the KCNJ8 genes have been found in $80 \%$ of the cases [van Bon et al., 2012; Czeschik et al., 2013]. Cantú syndrome is caused by gain-of-function mutations in the genes encoding the pore-forming (Kir6.1, KCNJ8) and regulatory (SUR2, ABCC9) subunits of the predominately cardiovascular isoforms of the $\mathrm{K}_{\mathrm{ATP}}$ sensitive channel [van Bon et al., 2012].

Two more entities with overlapping clinical features have also been described: acromegaloid facial appearance syndrome (AFA; OMIM 102150) and hypertrichosis with acromegaloid facial features (HAFF; OMIM 135400) [Dallapiccola et al., 1992; Czeschik et al., 2013]. The $A B C C 9$ gene has been recognized as the cause of Cantú syndrome. In suspected AFA and HAFF syndromes, even if they cannot be clearly distinguished clinically from

\section{KARGER}

E-Mail karger@karger.com

www.karger.com/msy
Helena Fryssira, MD, MSc, PhD

Medical Genetics, “Aghia Sophia” Children's Hospital, University of Athens

Thivon and Levadias Street

GR-11527 Athens (Greece)

E-Mail efrysira@med.uoa.gr 
Fig. 1. Full frontal view of the patient shows coarse acromegaloid facial characteristics (A). Hypoplasia of the second, third and fourth left toe distal phalanges (B). The right foot was normal.
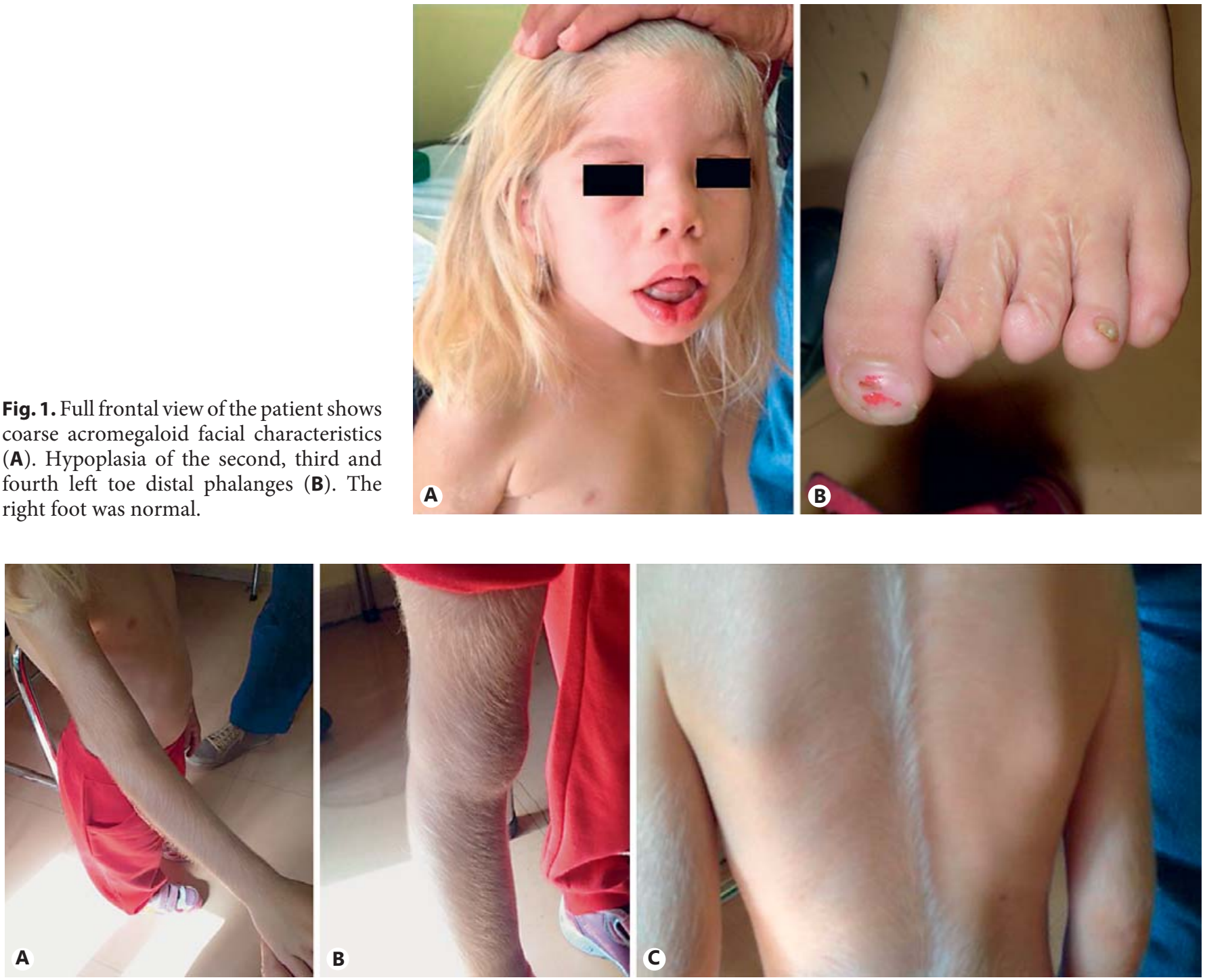

Fig. 2. Generalized hypertrichosis of the upper $(\mathbf{A})$ and lower limbs (B) and back (C) of the patient.

Cantú syndrome, mutation analysis of the $A B C C 9$ gene should be carried out to confirm the diagnosis as similar mutations can give rise to dissimilar phenotypes [Czeschik et al., 2013; Afifi et al., 2016].

In this study, we present a girl with clinical features of Cantú syndrome, who carries a mutation in the $A B C C 9$ gene along with additional previously unreported findings such as absent ovaries and a hypoplastic uterus. This could be an expansion of the phenotype and not attributed to mutations in other genes important for ovarian formation and function.

New Phenotypic Insights of Cantú Syndrome

\section{Case Report}

The female patient is the third child of healthy nonconsanguineous parents of Greek descent. The pregnancy was complicated by polyhydramnios, and the infant was born prematurely by normal delivery at 35 weeks of gestation. At birth, the infant displayed macrosomia (weight: 3,650 g [97th centile], length: $49 \mathrm{~cm}$ [90th centile], head circumference: $34.5 \mathrm{~cm}$ [97th centile]). At 14 days, she was admitted to a hospital due to hypotonia, feeding difficulties, and coarse facial characteristics. Generalized hypertrichosis, especially at the sacral region, was also observed.

The facial gestalt included: macrocephaly, thick and bushy eyebrows, epicanthal folds, a broad nasal bridge, a bulbus nose, a long philtrum, thick lips (particularly the lower lip), a short neck, and low-set ears (Fig. 1A). Subsequent metabolic testing for mucopolysaccharidoses and lysosomal storage diseases was negative. A con-

Mol Syndromol 2017;8:206-210 

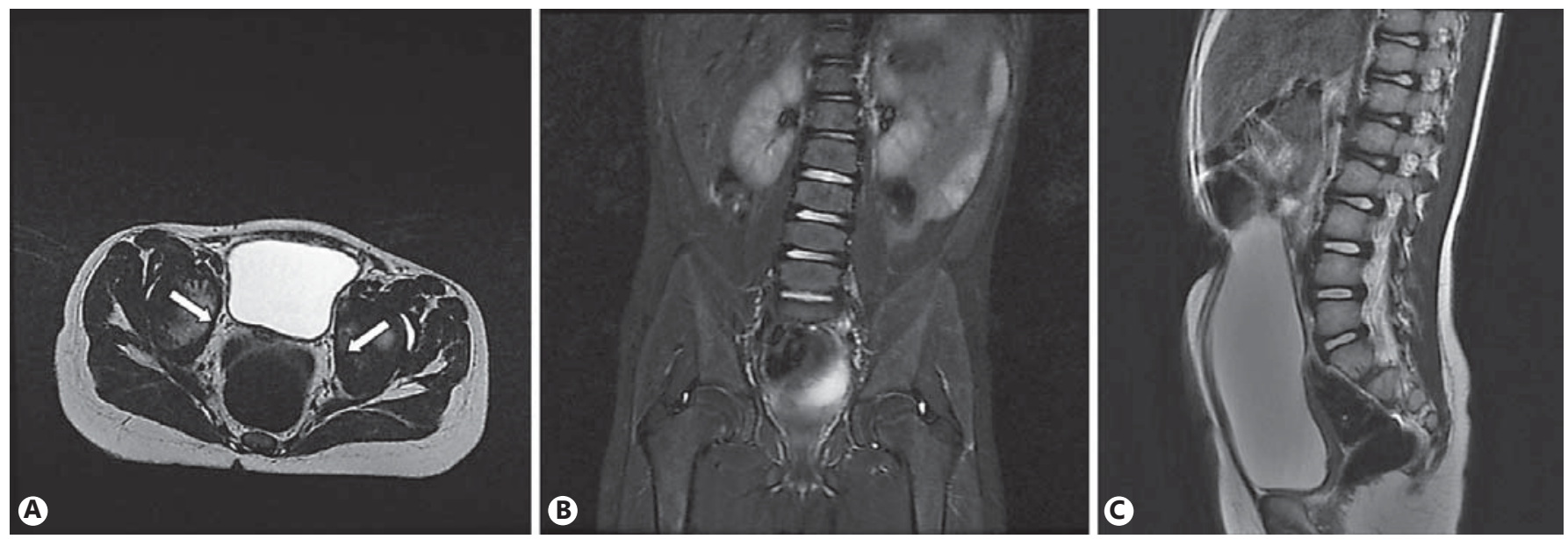

Fig. 3. A The uterus is hypoplastic and the ovaries do not exist (arrows). B, C A significant increase of the urinary bladder's craniocaudal diameter, which is up to L3 level, is shown.

genital infection panel work-up and thyroid function testing were also normal. Cardiac evaluation due to a heart murmur by ultrasound documented mild mitral regurgitation, a small patent ductus arteriosus, and patent foramen ovale. Furosemide treatment was initiated. Neurological evaluation revealed hypotonia. Brain ultrasound showed 2 small cysts of the choroid plexus with no clinical significance.

The infant was reevaluated regularly, and at 12 months, hypotonia showed a slight improvement as well as her heart problem. However, the generalized hypertrichosis and coarse facial features were still evident. At the age of 4 years, the clinical examination at the Clinical Genetic Unit showed borderline performance, macrocephaly (head circumference: $53 \mathrm{~cm}$ [90th centile]), while the rest of the somatometric measurements were within normal range (weight: $18 \mathrm{~kg}$ [25-50th centile], height: $110 \mathrm{~cm}$ [50th centile]). Our patient had a wide mouth, with continuous drooling and a protruding tongue with 2 frenulae on the upper and lower lips. The chest was markedly narrow with everted and supernumerary nipples. Joint laxity, deep palmar and plantar creases were observed. Hypoplasia was found only on the second, third, and fourth left toe phalanges (Fig. 1B). Generalized hypertrichosis was obvious (Fig. 2A-C). The external genitalia were normal. Cardiac reexamination by ultrasound was normal.

A second brain and lumbosacral MRI revealed no abnormalities. Ophthalmologic and auditory assessments were normal. The uterus was hypoplastic, but no ovaries were depicted by an ultrasound, and this was confirmed by an abdominal MRI in a 1.5 Tesla GE scanner, before and after intravenous administration of contrast agent (Fig. $3 \mathrm{~A}-\mathrm{C})$. Hematologic, biochemical, and endocrine testing such as follicle stimulating hormone: $1.37 \mathrm{mIU} / \mathrm{mL}$ (normal values: $<3.80$ ), prolactin: $30.51 \mathrm{ng} / \mathrm{mL}$ (normal values: 5-20), estradiol, luteinizing hormone, testosterone, DHEA-S, and $17-\mathrm{OH}$ progesterone were normal. Thyroid function, growth hormone, insulin-like growth factor, parathyroid hormone as well as vitamin $\mathrm{D}$ were also all normal (Table 1). A radiologic evaluation of the long bones was normal, and the bone age of the right hand using the Greulich-Pyle scale showed that the skeletal maturation was 1 year behind.
Table 1. The results of endocrine testing performed at age 4 years

\begin{tabular}{lll}
\hline Endocrine tests & Measurements & Normal values \\
\hline FSH & $1.37 \mathrm{mIU} / \mathrm{mL}$ & $<3.80$ \\
$\mathrm{LH}$ & $<0.100 \mathrm{mIU} / \mathrm{mL}$ & - \\
Estradiol & $<5 \mathrm{pg} / \mathrm{mL}$ & $<27.00$ \\
PRL & $30.51 \mathrm{ng} / \mathrm{mL}$ & $5-20$ \\
Testosterone & $<20 \mathrm{ng} / \mathrm{dL}$ & - \\
DHEA-S & $0.059 \mu \mathrm{g} / \mathrm{mL}$ & $<0.600$ \\
$17-\mathrm{OHP}$ & $0.560 \mathrm{ng} / \mathrm{mL}$ & $0.200-0.800$ \\
T3 & $130 \mathrm{mg} / \mathrm{dL}$ & $80-220$ \\
T4 & $8.99 \mathrm{mg} / \mathrm{dL}$ & $5-13$ \\
TSH & $2.10 \mu \mathrm{IU} / \mu \mathrm{L}$ & $0.5-5$ \\
PTH & $64.8 \mathrm{pg} / \mathrm{mL}$ & $12.0-80.0$ \\
$25-(\mathrm{OH}) \mathrm{D} 3$ & $19.90 \mathrm{pg} / \mathrm{mL}$ & $18.00-65.00$ \\
\hline
\end{tabular}

D3, vitamin D; DHEA-S, dehydroepiandrosterone sulfate; FSH, follicle stimulating hormone; $\mathrm{LH}$, luteinizing hormone; 17-OHP, 17-OH progesterone; $\mathrm{PRL}$, prolactin; $\mathrm{PTH}$, parathyroid hormone; T3/T4, thyroid hormones; TSH, thyroid-stimulating hormone.

\section{Methods}

Chromosomal analysis by G-banding technique revealed a normal female karyotype (46,XX).

A genomic DNA sample was extracted from the peripheral blood of both the patient and her parents following standard procedures. A sequencing analysis (Sanger sequencing) of the ABCC9 gene (NCBI: NM_02097.3) was performed using a standard methodology (Institute for Human Genetics, University Clinic, Essen, Germany).

Molecular analysis of the patient also included QF-PCR amplification (Devyser) and capillary electrophoresis on an AB13500 
automated sequencer. The data were processed with the Gene Marker 95 software. The QF-PCR mixes 1 and 2 contained primers specific for the $\mathrm{Y}$ chromosome regions such as $A M E L Y, Z F Y$, and $S R Y$ loci on the short arm.

Further investigation with aCGH was performed by hybridizing the sample against a male human reference commercial DNA sample (Promega Biotech) using an aCGH platform that included 60,000 oligonucleotides distributed across the entire genome (Agilent Technologies). For the majority of the genome, the average genomic power of resolution of this analysis was $200 \mathrm{~kb}$.

\section{Results}

The affected transcript was NM_005691.3 (ABCC9v001): c.3460C $>\mathrm{T}$ (p.Arg1154Trp) that resulted in the abnormal protein NM-005691.3 (ABCC9_1001): p.Arg1154Trp (http://humgenprojects.lumc.nl/trac/ mutlyser/wiki/NameChecker). This known missense mutation is located in exon 27 of the $A B C C 9$ gene in a heterozygous state. The parental DNA molecular analysis was normal.

No amplicons from the $\mathrm{Y}$ chromosome and especially the $S R Y$ gene were detected. The marker ratio of the informative pseudoautosomal XY chromosome STR markers (XY2 and XY3) confirmed the absence of the Y chromosome and a normal female sex constitution. The aCGH analysis was normal.

\section{Discussion}

This study describes a sporadic case of a girl with Cantú syndrome. Cantú syndrome has been considered as a new member of potassium channelopathies [van Bon et al., 2012]. The syndrome has been attributed to mutated ABCC 9 or KCNJ8 genes as the underlying causes. They are both located in the $12 \mathrm{p} 12.1$ gene cluster and encode the SUR2 and Kir6.1 subunits of ATP-dependent potassium channels ( $\mathrm{K}_{\mathrm{ATP}}$ channel) [van Bon et al., 2012]. Alternative RNA splicing of the terminal exon of the $A B C C$ gene produces a SUR2A isoform that is expressed in cardiac and skeletal muscles, while the SUR2B isoform is mainly expressed in smooth muscles. The biological role of $A B C C 9$ is protective against ischemic stress in the heart or skeletal muscle and regulates the vasomotor tone when energy supplies are low [Bryan et al., 2007; Flagg et al., 2010; Harakalova et al., 2012].

In Cantú syndrome, gain-of-function mutations in the Kir6.1 and SUR2 subunits of $\mathrm{K}_{\mathrm{ATP}}$ channels could explain the presence of cardiac hypertrophy, hypertrichosis and

New Phenotypic Insights of Cantú

Syndrome edema secondary to the vasodilating effect on smooth muscles [Bienengraeber et al., 2004; Grange et al., 2006; $\mathrm{Li}$ et al., 2013]. Loss-of-function mutations in the ABCC9 gene have been associated with an atrial fibrillation phenotype in one patient [Olson et al., 2007; Scurr et al., 2011], idiopathic dilated cardiomyopathy [Bienengraeber et al., 2004; Grange et al., 2006], and conduction abnormalities such as Brugada and early repolarization syndromes [Hu et al., 2014].

However, 28 of the 35 patients with Cantú syndrome reported so far who have undergone an $A B C C 9$ gene molecular analysis to date have been found to carry a heterozygous pathogenic variant with a gain-of-function effect at the protein level [Harakalova et al., 2012; van Bon et al., 2012]. Our patient carries a de novo c.3460C $>\mathrm{T}$ (R1154W) variant which is associated with the full phenotype of Cantú syndrome. This arginine-to-tryptophan substitution, in a highly conserved residue, in the second type 1 transmembrane domain of the ABCC9 protein which was not found in 5,000 exomes, indicated the pathogenic nature of the generating protein [van Bon et al., 2012]. The same mutation has been identified in an Egyptian girl with HAFF by Afifi et al. [2016]. The atypical and clinically distinct conditions of AFA and HAFF may belong to the milder end of the ABCC9 phenotype spectrum [Kini and Clayton-Smith, 2004; Czeschik et al., 2013].

Despite identification of the hotspot $A B C C 9$ variant, our patient demonstrated only mild cardiac involvement, with no pericardial effusion or lymphedema so far. However, data from medical literature suggest that cardiac hypertrophy and skeletal abnormalities are not always present at an early age due to the progressive nature of the disorder [Scurr et al., 2011; Hiraki et al., 2013]. The most common skeletal changes are calvarial thickness, wide ribs, platyspondyly, ischiopubic hypoplasia, bilateral coxa valga, and wide metaphyses. In our patient, a radiographic skeletal survey showed only wide ribs. Hypoplasia of only the second, third and fourth left toe distal phalanges was noted. This was attributed to annular constricting amniotic bands due to amnion rupture and small strands of amnion which constrict parts of the limbs and can result in deformity.

The important finding in our patient was the absence of the ovaries and hypoplastic uterus. So far, there are no reports of bilateral congenital ovarian agenesis in Cantú syndrome. In our patient, there is no family history of ovarian agenesis. Other causes of ovarian agenesis were ruled out since we had a female karyotype (46,XX), negative $S R Y$ testing, and a normal aCGH analysis. Therefore,

Mol Syndromol 2017;8:206-210 209 
the abnormal internal genitalia could represent an expansion of the Cantú phenotype and not be due to mutations or variations in other genes which could influence ovarian development.

Our findings further contribute to the delineation of the clinical phenotype of Cantú syndrome. Additional reports regarding urogenital and gonadal abnormalities with the $A B C C 9$ gene clinical spectrum are required in the future. Studies of such rare diseases could lead to a better understanding of the pathophysiology of ABCC9related syndromes. Appropriate genetic counseling and prenatal diagnosis for these patients and their families must also be stressed. We recommend regular follow-ups for our patient, especially for cardiac implications and endocrine manifestations as these symptoms of Cantú syndrome progress with age.

\section{Statement of Ethics}

The authors have no ethical conflicts to disclose.

\section{Disclosure Statement}

The authors have no conflicts of interest to declare.

\section{References}

Afifi HH, Abdel-Hamid MS, Eid MM, Mostafa IS, Abdel-Salam Ghada MH: De novo mutation in $A B C C 9$ causes hypertrichosis acromegaloid facial features disorder. Pediatr Dermatol 33:e109-113 (2016).

Bienengraeber $M$, Olson TM, Selivanov VA, Kathmann EC, O'Cochlain F, et al: ABCC9 mutations identified in human dilated cardiomyopathy disrupts catalytic $\mathrm{K}_{\mathrm{ATP}}$ channel gating. Nat Genet 36:382-387 (2004).

Bryan J, Muñoz A, Zhang X, Düfer M, Drews G, et al: $\mathrm{ABCC} 8$ and $\mathrm{ABCC} 9 \mathrm{ABC}$ transporters that regulate $\mathrm{K}^{+}$channels. Pflugers Arch 453: 703-718 (2007).

Cantú JM, Garcia-Cruz D, Sanchez-Corona J, Hernández A, Nazará Z: A distinct osteochondrodysplasia with hypertrichosis-individualization of a probable autosomal recessive entity. Hum Genet 60:36-41 (1982).

Czeschik JC, Voigt C, Goecke TO, Lüdecke HJ, Wagner $\mathrm{N}$, et al: Wide clinical variability in conditions with coarse facial features and hypertrichosis caused by mutations in ABCC 9 . Am J Med Genet A 161A:295-300 (2013).
Dallapiccola B, Zelante L, Accadia L, Mingarelli $\mathrm{R}$ : Acromegaloid facial appearance (AFA) syndrome: report of a second family. J Med Genet 29:419-422 (1992).

Flagg TP, Enkvetchakul D, Koster JC, Nichols CG: Muscle $\mathrm{K}_{\text {ATP }}$ channels: recent insights to energy sensing and myoprotection. Physiol Rev 90:799-829 (2010).

Grange DK, Lorch SM, Cole PL, Singh GK: Cantu syndrome in a woman and her two daughters: further confirmation of autosomal dominant inheritance and review of the cardiac manifestations. Am J Med Genet A 140:1673-1680 (2006).

Harakalova M, van Harssel JJ, Terhal PA, van Lieshout S, Duran K, et al: Dominant missense mutations in $A B C C 9$ cause Cantú syndrome. Nat Genet 44:793-796 (2012).

Hiraki Y, Miyatake S, Hayashidani M, Nishimura $\mathrm{Y}$, Matsuura $\mathrm{H}$, et al: Aortic aneurism and craniosynostosis in a family with Cantu syndrome. Am J Med Genet A 164A:231-236 (2013).
Hu D, Barajas-Martínez H, Terzic A, Park S, Pfeiffer $\mathrm{R}$, et al: $A B C C 9$ is a novel Brugada and early repolarization syndrome susceptibility gene. Int J Cardiol 171:431-442 (2014).

Kini U, Clayton-Smith J: Acromegaloid facial appearance syndrome. Clin Dysmorphol 13: 251-253 (2004).

Li A, Russell H, Knutsen BS, Zhang H, Osei-Owusu $\mathrm{P}$, et al: Hypotension due to Kir6.1 gain-offunction in vascular smooth muscle. J Am Heart Assoc 2:e000365 (2013).

Olson TM, Alekseev AE, Moreau C, Liu XK, Zingman LV, et al: $K_{\text {ATP }}$ channel mutation confers risk for vein of Marshall adrenergic atrial fibrillation. Nat Clin Pract Cardiovasc Med 4: 110-116 (2007).

Scurr I, Wilson L, Lees M, Robertson S, Kirk E, et al: Cantú syndrome: report of nine new cases and expansion of the clinical phenotype. Am J Med Genet A 155A:508-518 (2011).

van Bon BW, Gilissen C, Grange DK, Hennekam $\mathrm{RC}$, Kayserili $\mathrm{H}$, et al: Cantú syndrome is caused by mutations in ABCC 9 . Am J Hum Genet 90:1094-1101 (2012). 